\title{
The impact of hail storms on the agricultural economy of Cyprus and their characteristics
}

\author{
K. A. Nicolaides ${ }^{1}$, G. Photiou ${ }^{2}$, K. Savvidou ${ }^{1}$, A. Orphanou ${ }^{1}$, S. C. Michaelides ${ }^{1}$, T. S. Karakostas ${ }^{3}$, \\ D. Charalambous ${ }^{1,4}$, and C. Kannaouros ${ }^{2}$ \\ ${ }^{1}$ Meteorological Service, Nicosia, Cyprus \\ ${ }^{2}$ Agricultural Insurance Organization, Nicosia, Cyprus \\ ${ }^{3}$ Department of Meteorology and Climatology, Aristotle University of Thessaloniki, Thessaloniki, Greece \\ ${ }^{4}$ Department of Physics University of Lancaster, Lancaster, UK
}

Received: 22 January 2008 - Revised: 22 May 2008 - Accepted: 6 March 2009 - Published: 13 March 2009

\begin{abstract}
The contemporary economy of Cyprus is mostly based on services; agriculture was by tradition a strong contributor to the economy of the island, but nowadays its contribution is rather limited. At all times, the agricultural economy suffers from the consequences of weather phenomena such as hail, frost, drought, dust storms, etc. The present study focuses on the impact of hail to the agricultural economy, since hailstorms can straightforwardly destroy crops and plantations. Any knowledge concerning hail is useful for the improved understanding of the underlying thermodynamic and dynamic mechanisms and physical processes associated with its formation. For the investigation of hail as a natural hazard and its contribution to the insurance compensations paid to farmers, hail events and their associated synoptic and dynamic conditions were studied. Hail events were clustered into a "frontal instability hail events" and a "thermal instability hail events" clusters. The spatial distribution of the frequency of hail events was also determined in order to identify geographical areas that are more often hit by hail storms.
\end{abstract}

\section{Introduction}

The Agriculture Insurance Organization of Cyprus (A.I.O.) is a semi-governmental, non-profit oriented organization and offers compulsory insurance cover to farmers whose insured crops suffer damages from unavoidable natural hazards. The premium paid is shared between the Government and the in-

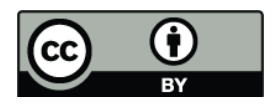

Correspondence to: K. A. Nicolaides (kleanthi@spidernet.com.cy) dividual farmer whose crop is insured. Hail is among the natural hazards A.I.O. compensates for.

The climatic characteristics of the area of the east Mediterranean are related to the medium and upper tropospheric circulation (Radinovic, 1987; Jacobeit, 1987) as a result of the combination of the subtropical highs to the south and the mid-latitude lows to the north and their seasonal latitudinal movement. Consequently, the area of the east Mediterranean is seasonally affected by depressions with baroclinic characteristics. The associated thundery activity sometimes results in hail with the subsequent damages to crops and plantations. Baroclinic depressions are frequent during the cold and relatively wet months, most of them invading from a westerly direction (Michaelides et al., 2004; Nicolaides et al., 2004; Nicolaides, 2005). During the long warm and dry period which lasts for 5 to 7 months, namely from April - May to September - October (Blanchet, 1976; Maheras, 1985), such baroclinic depressions are very rare (Kallos and Metaxas, 1980).

\section{Data and methodology}

In the present study, the compensation resulted from hail events which have been recorded by A.I.O. during the tenyear period from 1996 until 2005 are investigated. In this respect, the A.I.O. meteorological hazards and corresponding compensation paid database was used in order to investigate the economic aspect of the study.

Also, in order to identify the main dynamic and synoptic characteristics of the clusters, several parameters were examined (see Nicolaides, 2005). For the necessary mathematical calculations the NCEP/NCAR global analysis for 00:00 UTC, with a grid box size of $2.5^{\circ} \times 2.5^{\circ}$ were used.

Published by Copernicus Publications on behalf of the European Geosciences Union. 


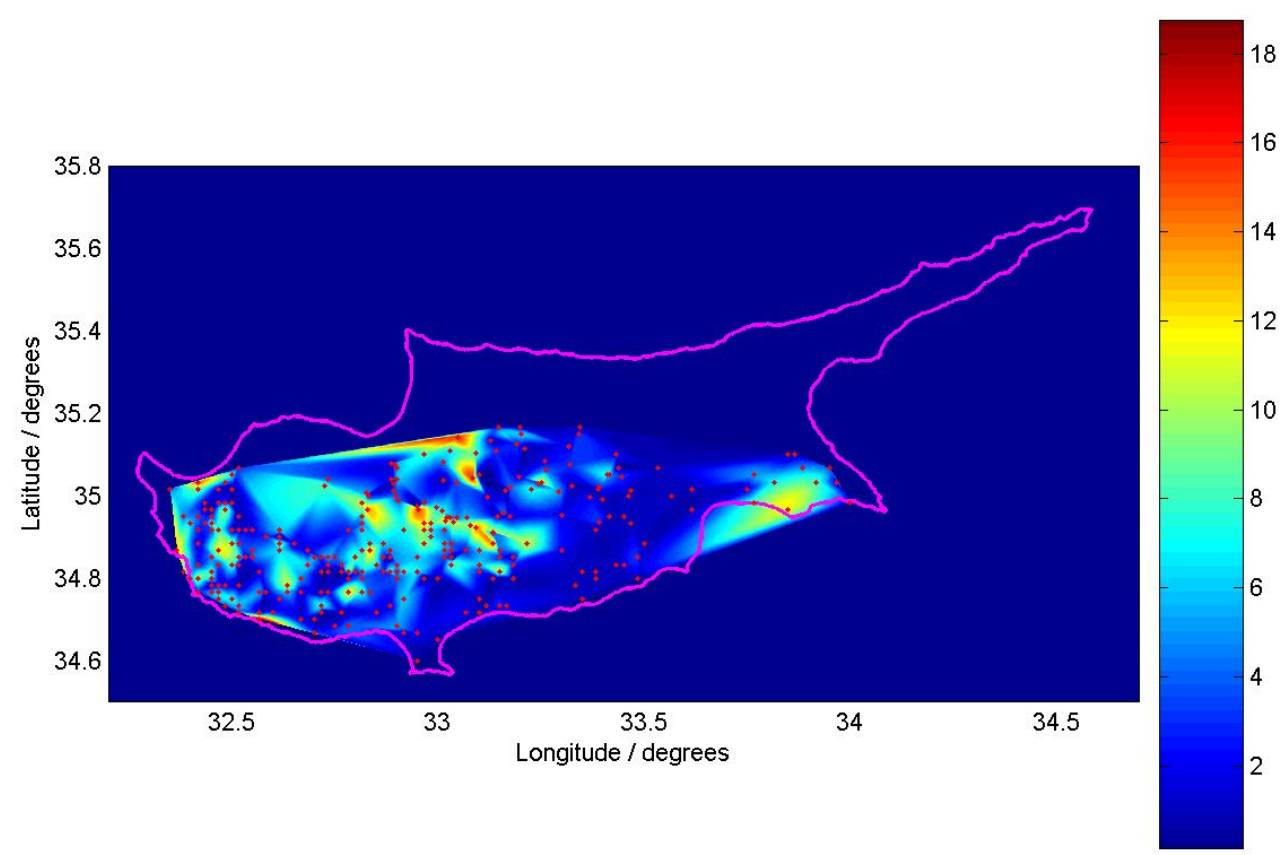

Fig. 1. The spatial distribution of the frequency of hail events in Cyprus that resulted in compensation by the A.I.O. Data is not available for the north part.

Specifically, the data used were the geodynamic height, temperature, and the $\mathrm{u}$ and $\mathrm{v}$ components of the horizontal wind vector at various isobaric surfaces. The mean fields of the geodynamic height, temperature, relative vorticity and divergence of the horizontal wind vector over the isobaric surfaces of 850,500 and $300 \mathrm{hPa}$ of the "thermal instability hail events" and the "frontal depression hail events" of the day prior to the hail event (D-1) the day of the hail event (D0) and the day after the hail event $(D+1)$ were reconstructed in order to identify any dynamic characteristics of hail storms and to create a useful tool for local weather forecasters. The calculations covered the area bounded by the meridians $20^{\circ} \mathrm{W}$ and $50^{\circ} \mathrm{E}$ and parallel circles $20^{\circ} \mathrm{N}$ and $65^{\circ} \mathrm{N}$.

\section{Results}

During the period from 1996 to 2005, 138 hail events have resulted in compensation by A.I.O. Most of the events, namely 93, occurred during the cold and relatively wet period, when frontal depressions affected the area of the east Mediterranean and were clustered as "frontal instability hail events". Only 45 events were recorded during the warm and dry period and were clustered as "thermal instability hail events". In order to determine the spatial distribution of the frequency of hail events over the area of Cyprus, an interpolation method based on Delaunay triangulation was employed, combined with a cubic surface fit to the data (for more information see Barber et al., 1996; Watson., 1992; De Berg et al.,
2008) The distribution (Fig. 1) exhibits several local maxima over Troodos mountains to the west of the island, which can be interpreted by the well known orographic effect on the enhancement of convective activity. Figure 1 also displays a frequency maximum over the area of Larnaca, on the southeast coast of the island. The distribution is relatively smooth with less frequent hail events over the main plain area in the centre of the island and over coastal regions.

\subsection{Synoptic characteristics}

There are 93 "frontal instability hail events"; these are associated with frontal depressions with occasionally intense baroclinic characteristics that are reaching the area mainly from the west direction during the cold months. During this period the area is experiencing relatively high pressure fields with a north-easterly air flow and also relatively low temperatures. Mean sea level pressure of $1020 \mathrm{hPa}$ and even higher is very common, while maximum temperatures below $15^{\circ} \mathrm{C}$ are also very common, at a time when the sea surface temperature is reaching just $16^{\circ}$ to $18^{\circ} \mathrm{C}$.

Only 45 cases belong to the "thermal instability hail events" cluster and are reported during the warm and dry months. During this period, the area of the east Mediterranean is under the influence of the extension of the seasonal low pressure, centred over the Tibetian plateau; mean sea level pressure of $1005 \mathrm{hPa}$ or even lower is very common over Cyprus. During this period, the area of Cyprus is also experiencing, relatively high temperatures. Maximum 
Table 1. Total and due to hail compensation paid per crop (in K EU).

\begin{tabular}{llllllll}
\hline $\begin{array}{l}\text { Crop } \\
\text { Compensation }\end{array}$ & Deciduous & Vines & Grains & Citrus & Evergreens & Potatoes & Other \\
\hline Due to Hail & 10784.9 & 4097.3 & 803.6 & 3872.9 & 177.4 & 2995.1 & 20.2 \\
Total & 11772.1 & 6498.9 & 29348.9 & 5826.5 & 230.0 & 25523.9 & 1001.0 \\
\hline
\end{tabular}

a)

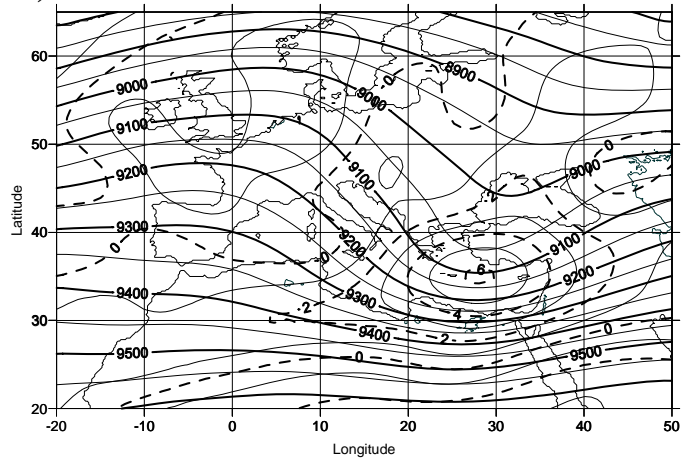

b)

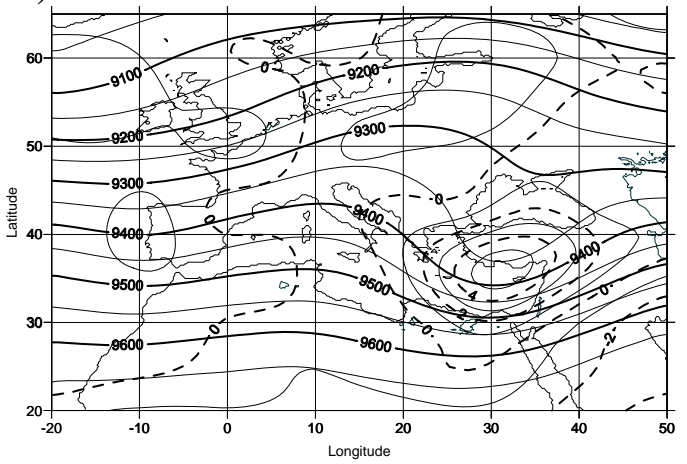

Fig. 2. The spatial distribution of the geopotential height (thick solid lines; units are gpm) and relative vorticity (thin solid and dotted lines; units are $10^{-5} \mathrm{~s}^{-1}$ ) over the isobaric surface of $300 \mathrm{hPa}$ at time D0, for the clusters of (a) "frontal instability hail events", and (b) "thermal instability hail events".

temperatures greater than $30^{\circ} \mathrm{C}$ over the coasts and greater than $36^{\circ} \mathrm{C}$ inland are very common, whereas, the sea surface temperature is reaching only $26^{\circ}$ to $28^{\circ} \mathrm{C}$.

\subsection{Dynamic characteristics}

From the investigation of the "frontal instability hail events" cluster, a strong relationship between the lower tropospheric instability (calculated but not presented) due to the warm Mediterranean Sea and lower tropospheric convergence was found (calculated but not presented), while the associated invading upper trough with baroclinic characteristics is supporting the system with the essential energy to develop hail storms. More specifically, from Fig. 2a representing the upper troposphere at time D0, an upper trough with its axis extending from north of the Black sea towards Crete and further southwestwards the north Africa coasts is clearly marked. The area of Cyprus has a typical geopotential height of $9075 \mathrm{gpm}$ and it is also characterized by upper cyclonic relative vorticity with a typical value of $5 \times 10^{-5} \mathrm{~s}^{-1}$. The investigation shows a decrease of the geodynamic height (constructed but not presented) and a corresponding increase of the values of the field of relative vorticity (calculated but not presented) if also compared with the same time. From the investigation over the mid tropospheric level of $500 \mathrm{hPa}$, a trough was found at time D-1 (constructed but not presented), invading the area of the east Mediterranean from the west and sharpening and deepening at time D0 (reconstructed but not presented).

A dynamic investigation has also been performed for the "thermal instability hail events" cluster. A strong correlation was found between the lower tropospheric convergence (calculated but not presented) over land (lower tropospheric instability over land during warm months acts as a triggering mechanism for lower tropospheric convergence due to the lands relatively high temperature if compared to the sea surface temperature) and hail storms at there early stages. A weak upper trough associated with positive vorticity advection was also found to be accountable for further development (see Fig. 2b for time D0). The axis of the trough is extending from the Crimean peninsula towards southwest Minor Asia and further southwards to Egypt. A typical geodynamic height over the area of Cyprus is $9400 \mathrm{gpm}$ (i.e. more than $300 \mathrm{gpm}$ higher than the corresponding height of D0 of the "frontal instability hail events" cluster). From Fig. 2a and $\mathrm{b}$ it is noted that the upper cyclonic vorticity over the area of Cyprus has a value of $5 \times 10^{-5} \mathrm{~s}^{-1}$, as typical for both clusters corresponding to D0. It is also worth noting that the "thermal instability hail events" are initiated from lower tropospheric instability while the upper dynamics assist further development and conservation. 


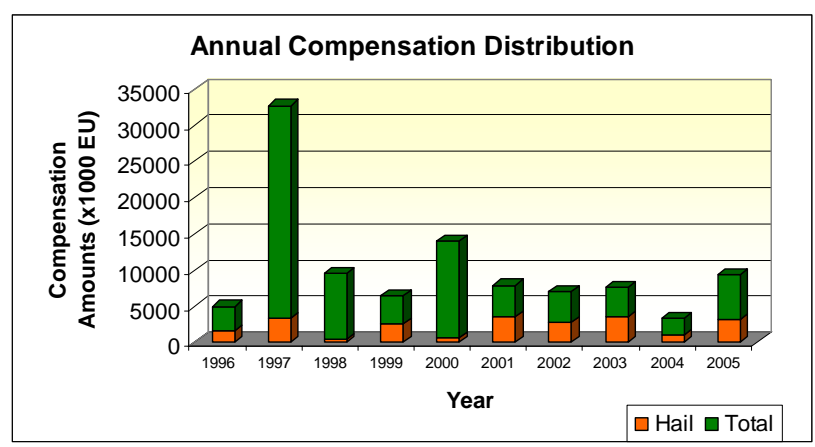

Fig. 3. The annual compensation paid by A.I.O. during the period of study for all meteorological hazards and the fraction due to hail.

\subsection{Agro Economic impact}

The premium paid to A.I.O is shared between the Government and the individual farmer whose crop is insured. The total amount for all compensations paid to farmers during the years 1996 to 2005 amounts to 80.2 million Euros. Compensations were paid for a large spectrum of natural hazards causing crop damage; almost all causes are attributed to weather hazards, such as hail, drought, wind, heat wave, floods and frost. The amount paid to farmers due to hail damages during the aforementioned period is 22.7 million Euros. Therefore, the compensations due to hail occurrences amounts to almost $28.4 \%$ of the total compensations paid.

The annual amount of compensations paid during the study period and the hail contribution is presented in Fig. 3. The compensation paid during 1997 was the maximum (29 421.5 K EU) of the study period. Drought and high temperatures have high contribution to the formulation of the compensation paid for 1997. The minimum compensation paid was during 2004 (2199 K EU). The maximum compensation paid due to hail was during 2001 (3614.5 K EU) and the minimum in 1998 (464 K EU).

Figure 4 displays the distribution of hail events clustered as "thermal instability hail events" and "frontal instability hail events" during the study period. It is observed that the number of both the "Thermal" and "Frontal" hail events increases with time during the study period; however, the increase of the number of "frontal instability hail events" is greater compared with the increase of the number of the "thermal instability hail events".

In Table 1 the compensation paid per crop and the contribution of hail for the study period is presented. The maximum total compensation is paid for grains (i.e. $29348.9 \mathrm{KEU}$ ) and potatoes (i.e. $25523.9 \mathrm{KEU}$ ). Deciduous plantations absorb a significant amount of compensation (i.e. $11772.1 \mathrm{KEU}$ ), while, the compensation paid for evergreens and other crops is less during the period of study.

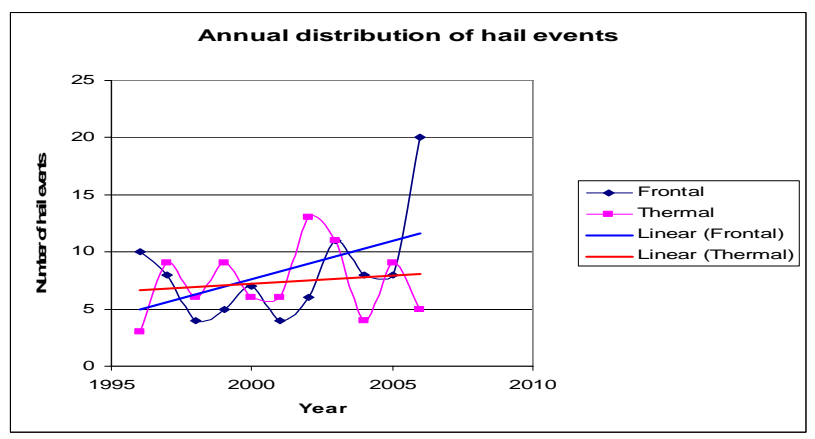

Fig. 4. The annual distribution of the number of hail events clustered as "Frontal" and "Thermal" which have resulted in compensation by A.I.O during the period of study.

Hail was found to be the most damaging factor to deciduous plantations (Table 1). These plantations are found over the Troodos mountainous region. Their blossom begins during spring, the transition period between the cold and the warm period and their fruit production starts during the early warm period. Compensation paid for hail amounts to $10784.9 \mathrm{KEU}$ or $91.6 \%$ of the total compensation paid for deciduous plantations for the period of study for all hazards. Also note from Table 1 that the compensation paid for citrus (i.e. $5826.5 \mathrm{~K} \mathrm{EU}$ ) and vines (i.e. $6498.2 \mathrm{~K} \mathrm{EU}$ ) is generally small compared to deciduous, potatoes and grains. It is important to note that the contribution of hail to compensation paid for citrus (i.e. $3872.9 \mathrm{~K} \mathrm{EU}$ ) and vines (i.e. $4097.3 \mathrm{KEU}$ ) is high since it amounts to $66.5 \%$ and $63 \%$, respectively. Vine plantations are mainly found over the Troodos range, while citrus are found mainly over the main plain area and the coasts of the island. It worth noting the remarkable role of the Troodos range in the contribution of hail to the total compensation paid during the period of study. Also, different kind of plantations are affected by different clusters of hail events: deciduous are primarily affected by thermal instability hail events, while frontal instability hail events are responsible for the high compensation for potatoes plantation.

\section{Concluding remarks}

Hail is a hazardous weather element that can cause considerable losses to the agricultural economy but can also cause damage to other human activities. The impact of hail on the above is directly related to its severity.

Agricultural production is an economic domain which is greatly affected by hail storms. Damages due to hail which are compensated by the A.I.O. amount to 22.7 million EU; this compensation represents $28 \%$ of the total agricultural compensations paid due to adverse growing conditions (a considerable number of which are directly attributed to 
weather). Mountainous plantations, like deciduous trees and vines are the kind of plantations which are mostly affected by hail storms since its contribution to the total compensation is the greatest.

The dominant favorable weather conditions for hail events are either the presence of a frontal depression or a convectional weather type. According to these two factors, hail events were classified into two clusters; the "frontal instability hail events" cluster which comprises widespread hail events occurring during the cold season and the "thermal instability hail events" cluster which comprises isolated hail events occurring during the warm period. A significant contributor for the "frontal instability" cluster is the warm sea, triggering and maintaining lower tropospheric convergence, while for the "thermal instability" cluster the dominant triggering mechanism is the convective process initiated from the lower tropospheric convergence and assisted by the weak upper baroclinicity of the troposphere. Also, the presence of the Troodos range covering the western part of the island acts as a triggering mechanism both during the cold and warm period.

Edited by: A. Mugnai

Reviewed by: K. Lagouvardos

\section{References}

Barber, C. B., Dobkin, D. P., and Huhdanpaa, H. T.: The Quickhull Algorithm for Convex Hulls, ACM T. Math. Software, 22, 4, 469-483, Dec. 1996.

Blanchet, G.: Le temps au Liban. Approche d'une Climatologie Synoptique, Thèse 3ème Cycle, Lyon. T.I., 447 (text et tab.) \& T.II (Atlas), 1976.

de Berg, M., Cheong, O., van Kreveld, M., and Overmars, M.: Computational Geometry: Algorithms and Applications, Springer-Verlag, 191-218, 2008.

Jacobeit, J.: Variations of trough position and precipitation patterns in the Mediterranean area, J. Climatol., 7, 453-476, 1987.

Kallos, G. and Metaxas, D. A.: Synoptic processes for the formation of Cyprus lows, Riv. Meteorol. Aeronau., XL(2-3), 121138, 1980.

Maheras, P. : A factorial analysis of Mediterranean precipitation, Arch. Meteor. Geophy. B., 36, 1-14, 1985.

Michaelides, S., Nicolaides, K., and Karacostas, T.: Statistical characteristics of the cold season depressions over the area of Cyprus, Meteorologický èasopis 7, 61-66, 2004.

Nicolaides, K.: Synoptic and dynamic study of the depression cases affected the wider area of Cyprus during cold months, $\mathrm{PhD}$ thesis, Aristotle University, Thessaloniki, Greece, 2005 (in Greek).

Nicolaides, K., Michaelides, S., and Karacostas, T.: Spatial distribution of some dynamic parameters during the evolution of selected depressions over the area of Cyprus, Int. J. Climatol., 24, 1829-1844, 2004.

Radinovic, D.: Mediterranean cyclones and their influence on the weather and climate, PSMP Rep Series 24, WMO, Geneva, Switzerland, 131 pp., 1987.

Watson, D. E.: Contouring: A Guide to the Analysis and Display of Spatial Data, Tarrytown, NY: Pergamon (Elsevier Science, Inc.), 101-162, 1992. 